\begin{tabular}{|c|c|}
\hline Title & Formation of an ozone lamina due to differential advection revealed by intensive observations \\
\hline Author(s) & Tomikawa, Y oshihiro; Sato, Kaoru; Kita, Kazuyuki; Fujiwara, Masatomo; Y amamori, Miho; Sano, Takuki \\
\hline Citation & $\begin{array}{l}\text { Journal of Geophysical Research: A tmospheres, 107(D10), A CL 12-1-A CL 12-10 } \\
\text { https://doi.org/10.1029/2001DD000386 }\end{array}$ \\
\hline Issue Date & $2002-05-27$ \\
\hline Doc URL & http:/hdl .handle.net/2115/64857 \\
\hline Rights & Copyright 2002 A merican Geophysical Union. \\
\hline Type & article \\
\hline File Information & Tomikawa_et_al-2002-Journal_of_Geophysical_Research_A tmospheres_(1984_2012).pdf \\
\hline
\end{tabular}

Instructions for use 


\title{
Formation of an ozone lamina due to differential advection revealed by intensive observations
}

\author{
Yoshihiro Tomikawa, ${ }^{1}$ Kaoru Sato, ${ }^{2}$ Kazuyuki Kita, ${ }^{1}$ Masatomo Fujiwara, ${ }^{3}$ \\ Miho Yamamori, ${ }^{4}$ and Takuki Sano ${ }^{5}$ \\ Received 17 January 2001; revised 2 August 2001; accepted 17 September 2001; published 23 May 2002.
}

[1] An intensive observation with ozonesondes, radiosondes, and the Middle and Upper atmosphere (MU) radar was conducted at Shigaraki $\left(34.9^{\circ} \mathrm{N}, 136.1^{\circ} \mathrm{E}\right)$, Japan, from 16 through 24 April 1998 to investigate the formation mechanism of ozone laminae in the midlatitude lower stratosphere. In these observations the temporal variation of an ozone lamina at Shigaraki was continuously observed through a short time interval of 8 hours. During the observation period an ozone lamina with a thickness of $2-3 \mathrm{~km}$ appeared and ascended with a speed of $\sim 1 \mathrm{~km} \mathrm{day}^{-1}$ in the height region of $18-21 \mathrm{~km}$. It is deduced that inertia gravity waves existing in this height region did not contribute to formation of the ozone lamina, because their amplitudes were too small and their vertical phase propagation was in the opposite direction. The reverse domain filling method was used to reconstruct the "high-resolution" modified potential vorticity field using backward trajectory calculations. The results indicate that this ozone lamina was caused by differential advection due to the vertical shear associated with the subtropical westerly jet and embedded stationary Rossby wave therein. This means that large-scale motions concurrent with vertical wind shear can produce much smaller-scale structures in material fields than those of the large-scale motions themselves. INDEX TERMS: 0341Atmospheric Composition and Structure: Middle atmosphere - constituent transport and chemistry (3334); 3334 Meteorology and Atmospheric Dynamics: Middle atmosphere dynamics (0341, 0342); 3364 Meteorology and Atmospheric Dynamics: Synoptic-scale meteorology; 3384 Meteorology and Atmospheric Dynamics; Waves and tides; KEYWORDS: differential advection, ozone lamina, potential vorticity, reverse domain filling, ozonesonde observation, inertia-gravity wave

\section{Introduction}

[2] A decline of total ozone has been observed in northern midlatitudes during the last 2 decades [World Meteorological Organization, 1998]. It has been argued that the ozone depletion observed in northern midlatitudes may be induced by the mixing of chemically activated air from the polar vortex into midlatitudes in the form of laminae or filaments [Tuck et al., 1992]. Knudsen and Groo $\beta$ [2000] examined the transport of ozone-depleted air from the Arctic vortex into midlatitudes and showed that the intrusion of ozone-depleted air into midlatitudes can explain $\sim 40 \%$ of the ozone depletion in northern midlatitudes.

[3] The existence of laminated structures in ozone vertical profiles obtained by ozonesonde observations has long been recognized. Previous statistical studies have shown that such ozone laminae are most frequently observed from winter to spring in the lower stratosphere at middle and high latitudes and suggested that they mostly originate near the winter polar vortex and/or the

\footnotetext{
${ }^{1}$ Research Center for Advanced Science and Technology, University of Tokyo, Tokyo, Japan.

${ }^{2}$ National Institute of Polar Research, Tokyo, Japan.

${ }^{3}$ Radio Science Center for Space and Atmosphere, Kyoto University, Kyoto, Japan.

${ }^{4}$ Center for Climate System Research, University of Tokyo, Tokyo, Japan.

${ }^{5}$ Earth Observation Research Center, National Space Development Agency of Japan, Tokyo, Japan.
}

Copyright 2002 by the American Geophysical Union. 0148-0227/02/2001JD000386 subtropical westerly jet with a large gradient of ozone mixing ratio [Dobson, 1973; Reid and Vaughan, 1991, 1993].

[4] In the absence of chemical source and sink the ozone mixing ratio is approximately preserved for motions following air parcels over a few weeks in the midlatitude lower stratosphere. Thus most of the ozone laminae appear to be caused by dynamical processes such as differential advection across the large gradient of ozone mixing ratio. Gravity waves and Rossby waves have been proposed as processes to make ozone laminae by differential advection [Holton, 1987; Pierce and Grant, 1998]. Analyzing the data from the European Arctic Stratospheric Experiment (EASOE) conducted in the Arctic during winter 1991-1992, Teitelbaum et al. [1996] suggested that the ozone laminae could be formed by vertical and meridional motions associated with gravity waves. Such a relation between ozone laminae and gravity waves has been reported in several papers [e.g., Danielsen et al., 1991; Teitelbaum et al., 1994]. However, it is also reported that the amplitudes of waves seemed too small to form the laminated structures [Reid et al., 1994; Gibson-Wilde et al., 1997]. Newman and Schoeberl [1995] reanalyzed the ozone laminae observed during the NASA Stratosphere Troposphere Exchange Project (STEP) Mid-Latitude Field Experiment and suggested that the ozone laminae are attributed to differential advection due to synoptic-scale Rossby waves. Juckes and McIntyre [1987] showed that planetary wave breaking leads to the formation of a horizontally filamentary structure. These structures cannot maintain vertical coherence in a flow with significant vertical shear, leading to the formation of vertically laminated structures. Using contour advection with surgery and the reverse domain filling technique based on the analyzed winds, it was shown that the filamentary structures caused by wave breaking lead to laminated structures of tracers and are in good agreement with tracer observations at middle and high latitudes in the North- 


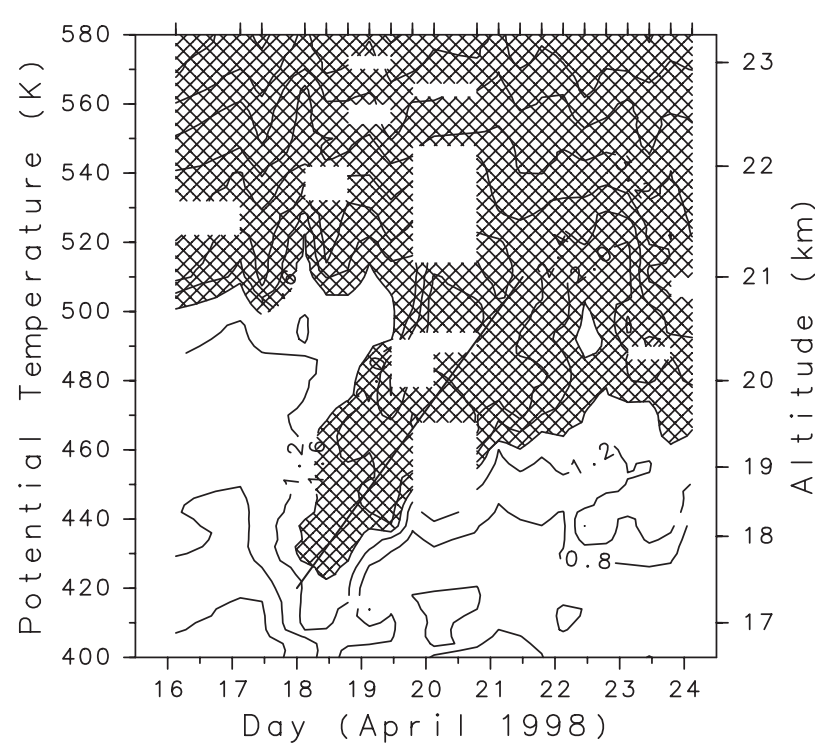

Figure 1. Time-height section of ozone mixing ratio (ppmv) over Shigaraki. The left and right axes represent the potential temperature and roughly corresponding altitude, respectively. Contour intervals are 0.4 ppmv. Regions with values larger than $1.6 \mathrm{ppmv}$ are shaded. A thick solid line indicates an approximate position of ozone extrema. Dates of ozonesonde observation are marked on the top axis.

ern Hemisphere [Waugh et al., 1994; Plumb et al., 1994; Orsolini, 1995; Orsolini et al., 1997; Newman et al., 1996; Mariotti et al., 1997].

[5] Most of the previous studies were based on instantaneous or short-term profiles of tracer distribution (e.g., ozonesonde and aircraft observations). Thus we conducted an observation satisfying the following three conditions: (1) a long enough term (9 days) and (2) a sufficiently high temporal resolution ( 8 hours) to observe a temporal variation of ozone laminae at one location; and (3) simultaneous observation of dynamical quantities such as temperature and winds to examine the contribution of gravity waves.

[6] In this paper, we describe several characteristics of an ozone lamina observed at Shigaraki $\left(34.9^{\circ} \mathrm{N}, 136.1^{\circ} \mathrm{E}\right)$, Japan, in April 1998 and examine possible causes of its formation. Details of the observation and obtained data are summarized in section 2 . The characteristics of the ozone lamina are described in section 3 . The contribution of inertia-gravity waves to the formation of the ozone lamina is examined in section 4 . To show the contribution of large-scale motions, a backward trajectory analysis and reverse domain filling calculations are performed in section 5. Finally, a summary and concluding remarks are presented in section 6 .

\section{Observation}

[7] An intensive observation with ozonesondes, radiosondes, and the Middle and Upper atmosphere (MU) radar, one of the mesosphere-stratosphere-troposphere (MST) radars, was conducted at Shigaraki $\left(34.9^{\circ} \mathrm{N}, 136.1^{\circ} \mathrm{E}\right)$, Japan, from 16 through 24 April 1998. Vaisala RS-80 radiosondes were used to measure vertical profiles of atmospheric pressure and temperature. Vertical distributions of atmospheric ozone concentration were obtained with EN-SCI balloon-borne electrochemical concentration cell (ECC) ozonesondes connected to the Vaisala RS-80 radiosondes [Komhyr et al., 1995]. We launched 24 ozonesondes and 25 radiosondes in total every 4 hours alternately during the observation period. Most of them reached altitudes over $30 \mathrm{~km}$. As a result, 4-hourly temperature and 8-hourly ozone concentration profiles for the 9-day period were obtained. The data sampling time was $\sim 1 \mathrm{~s}$ and the ascending speed of the sondes was $\sim 5 \mathrm{~m} \mathrm{~s}^{-1}$. In this paper, we use data interpolated at a constant vertical interval of $50 \mathrm{~m}$, so as to make the analysis easier.

[8] Continuous wind measurements were made with the MU radar in the height region of $1-24 \mathrm{~km}$ during the observation period. One vertical and four oblique beams pointing to the north, east, south, and west with the same zenith angle of $10^{\circ}$ were used to obtain three-dimensional winds. The spatial resolution along the beams was $150 \mathrm{~m}$. The time resolution of on-line observation data was $\sim 1 \mathrm{~min}$. In this study, data were processed off-line by the method developed by Sato et al. [1997] that allows us to estimate winds at higher levels than the standard on-line method, although the time resolution is reduced to $30 \mathrm{~min}$. Since the accuracy of the line-of-sight wind component is $\sim 0.1 \mathrm{~m} \mathrm{~s}^{-1}$, those of horizontal and vertical winds are $\sim 0.6\left(\approx 0.1 / \sin 10^{\circ}\right)$ and $0.1 \mathrm{~m} \mathrm{~s}^{-1}$, respectively. Details of the MU radar system are described by Fukao et al. [1985].

\section{Variations of Ozone Mixing Ratio}

[9] Figure 1 shows the time-height section of ozone mixing ratio obtained by ozonesonde observations at Shigaraki. Potential temperature $(\theta)$ is used as the vertical coordinate. Corresponding altitudes are also roughly shown on the right. An ozone-enhanced layer with a thickness of $40-60 \mathrm{~K}$ in $\theta(2-3 \mathrm{~km}$ in height) appeared at a level of $\theta=430 \mathrm{~K}(17-18 \mathrm{~km})$ on 18 April, and the layer ascended until 21 April with a speed of $\sim 25 \mathrm{~K} \mathrm{~d}^{-1}$ $\left(\approx 1 \mathrm{~km} \mathrm{~d}^{-1}\right)$. An ozone-depleted layer was also seen above the ozone-enhanced layer. The ozone mixing ratio at $460 \mathrm{~K}$ varied from $0.9 \mathrm{ppmv}$ (parts per million by volume) to $2.1 \mathrm{ppmv}$ during the observation period.

[10] Figure 2 shows the time evolution of the total ozone measured by total ozone mapping spectrometer onboard the Earth Probe satellite (EP/TOMS) at the closest grid point to Shigaraki

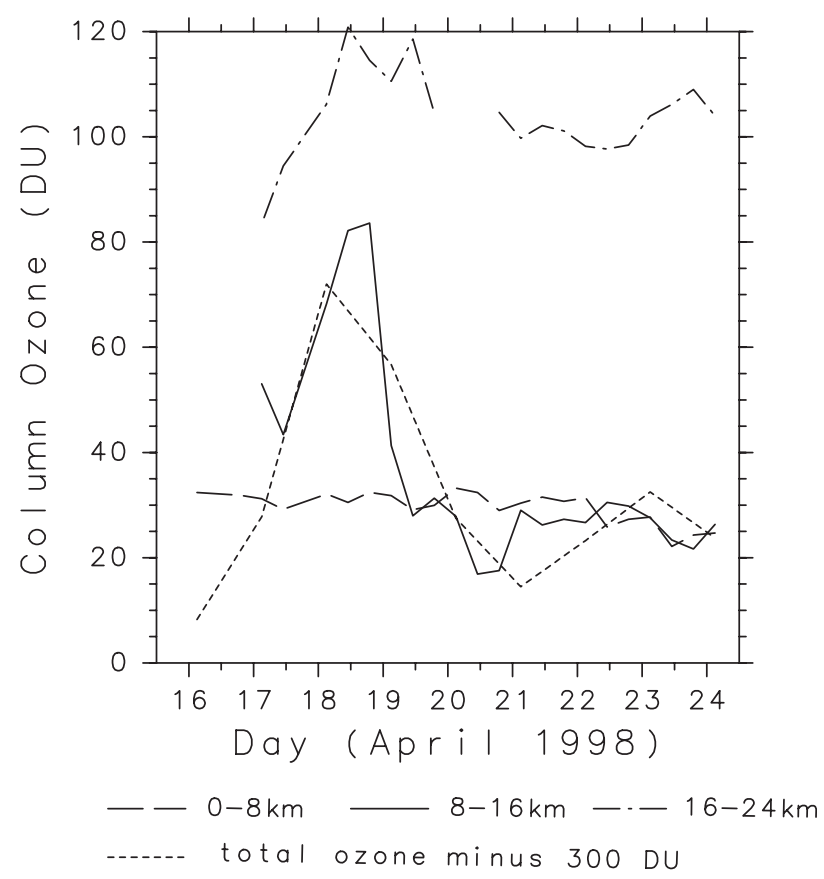

Figure 2. Temporal variation of column ozone amounts in three height regions $(0-8,8-16$, and $16-24 \mathrm{~km})$ and the total ozone measured by the EP/TOMS. The dashed, solid, dotted-dashed, and dotted lines show the column ozone amounts in $0-8,8-16$, and $16-24 \mathrm{~km}$ height regions and the total ozone minus $300 \mathrm{DU}$ $\left(1 \mathrm{DU}=2.687 \times 10^{16}\right.$ molecules of ozone per $\left.\mathrm{cm}^{2}\right)$, respectively. 

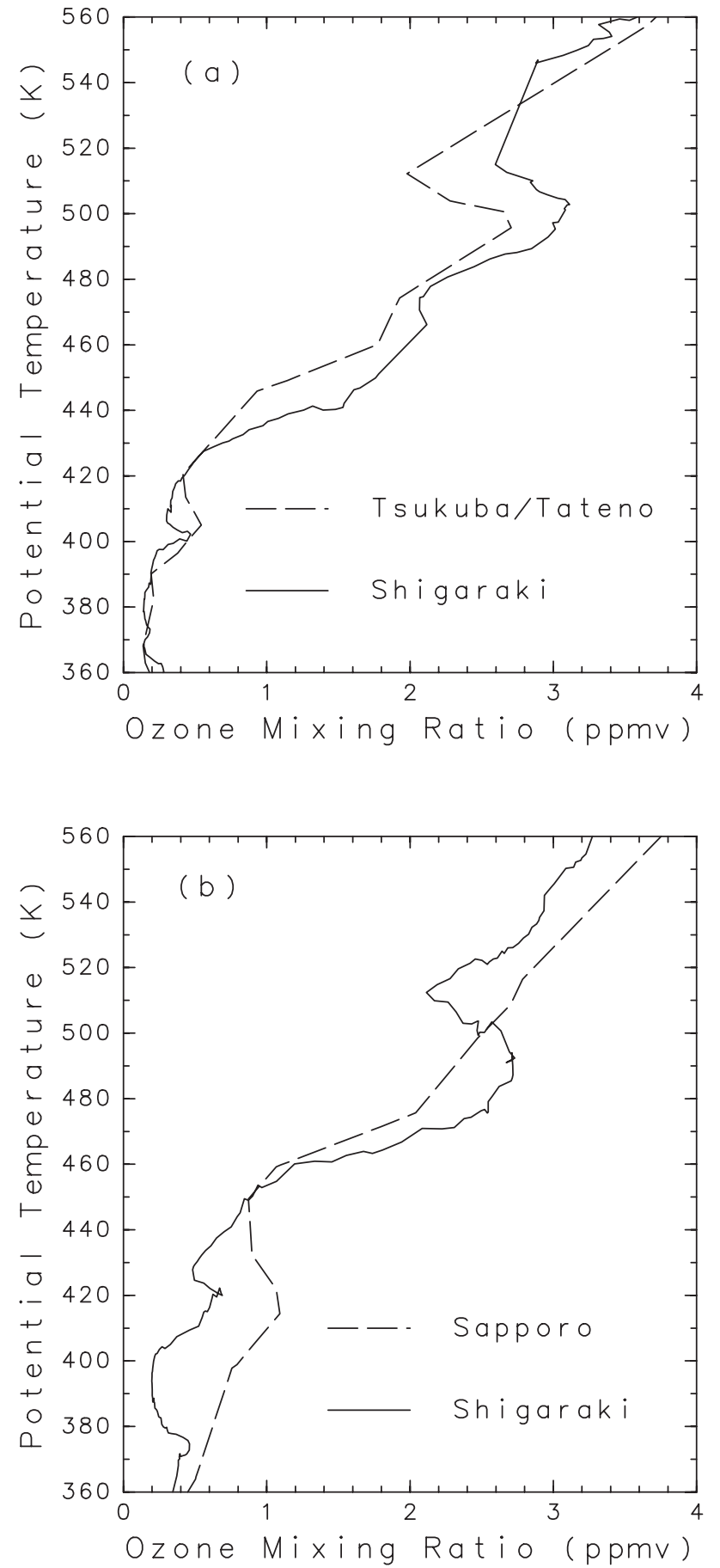

Figure 3. Vertical profiles of ozone mixing ratio measured on (a) 20 and (b) 21 April 1998. The solid lines show the ozone mixing ratio measured at $0300 \mathrm{UT}$ at Shigaraki $\left(34.9^{\circ} \mathrm{N}, 136.1^{\circ} \mathrm{E}\right)$, and the dashed lines at $0600 \mathrm{UT}$ of respective days in (a) Tsukuba/Tateno $\left(36.1^{\circ} \mathrm{N}, 140.1^{\circ} \mathrm{E}\right)$ and (b) Sapporo $\left(40.1^{\circ} \mathrm{N}, 141.3^{\circ} \mathrm{E}\right)$.

and the column ozone amounts in the three height regions $(0-8$, $8-16$, and $16-24 \mathrm{~km}$ ) calculated from the ozonesonde data. The height regions of $0-8,8-16$, and $16-24 \mathrm{~km}$ represent the troposphere, a marginal region including the tropopause, and the lower stratosphere including the region of ozone lamina, respectively. The total ozone increased by 50 DU from 17 to 18 April and decreased to the initial value by 21 April. The column ozone amounts in the height regions of $8-16$ and $16-24 \mathrm{~km}$ also increased by 40 and 35 DU during 17-18 April, respectively. The column ozone amount at $0-8 \mathrm{~km}$, on the other hand, was nearly constant during the observation period. The variation of the column ozone amount in the $8-24 \mathrm{~km}$ region can account for most of the total ozone variation. The variation of column ozone amount in the $8-16 \mathrm{~km}$ region is very large because of the variation of tropopause height. An important point is that the variation in the 16-24 km region was also significantly large during the observation period. Especially, the contribution of the $16-24 \mathrm{~km}$ region to the total ozone variation was roughly comparable to that of the $8-16 \mathrm{~km}$ region before the total ozone was maximized. This fact indicates that the appearance of the observed ozone lamina significantly contributed to the total ozone variation. The column
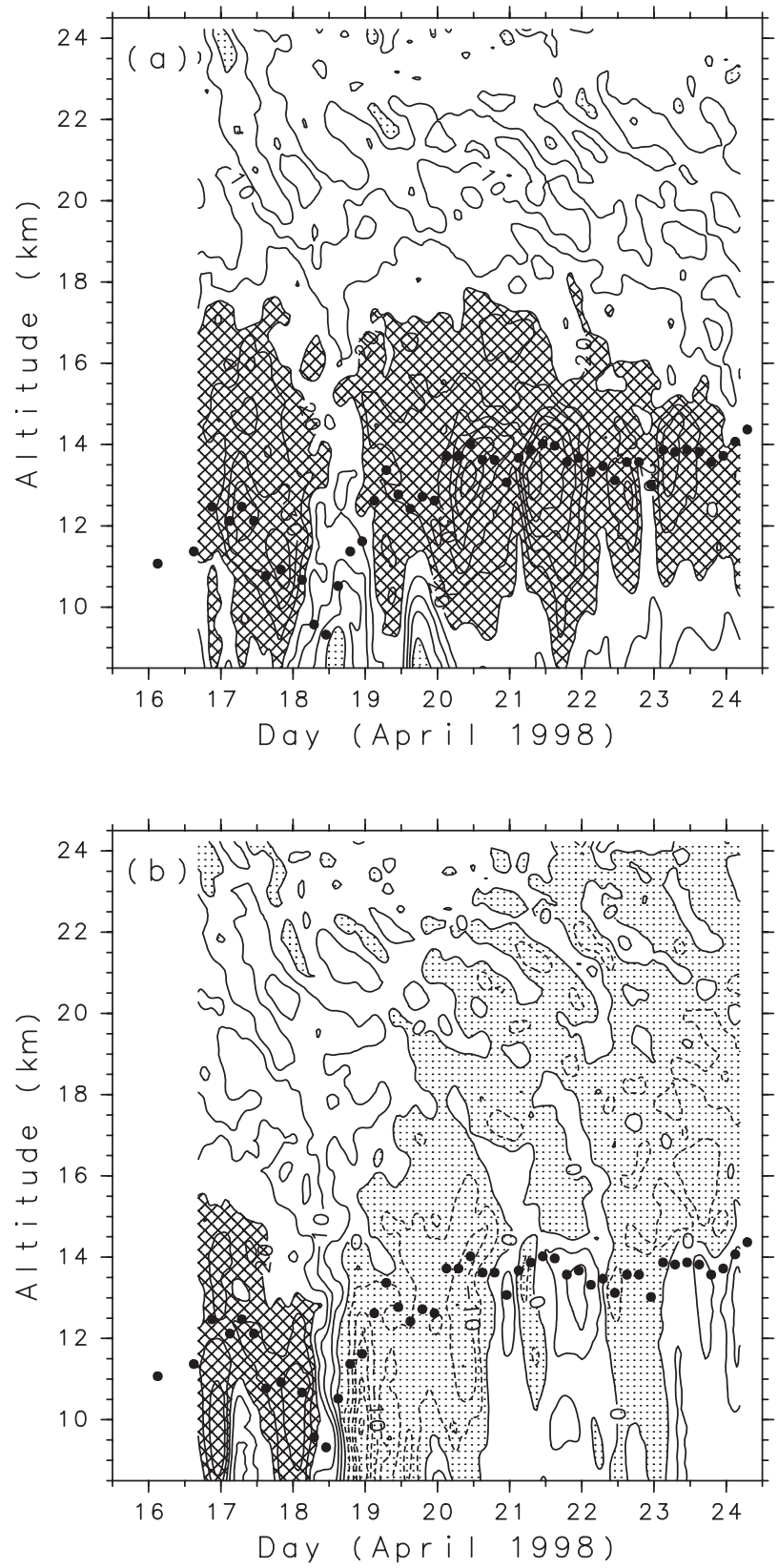

Figure 4. Time-height sections of (a) zonal and (b) meridional winds measured by the MU radar. Solid circles indicate tropopause levels determined by temperature lapse rate based on radiosonde data. Contour intervals are $5 \mathrm{~m} \mathrm{~s}^{-1}$. Negative regions are lightly shaded, and regions with values larger than $20 \mathrm{~m} \mathrm{~s}^{-1}$ are darkly shaded. 

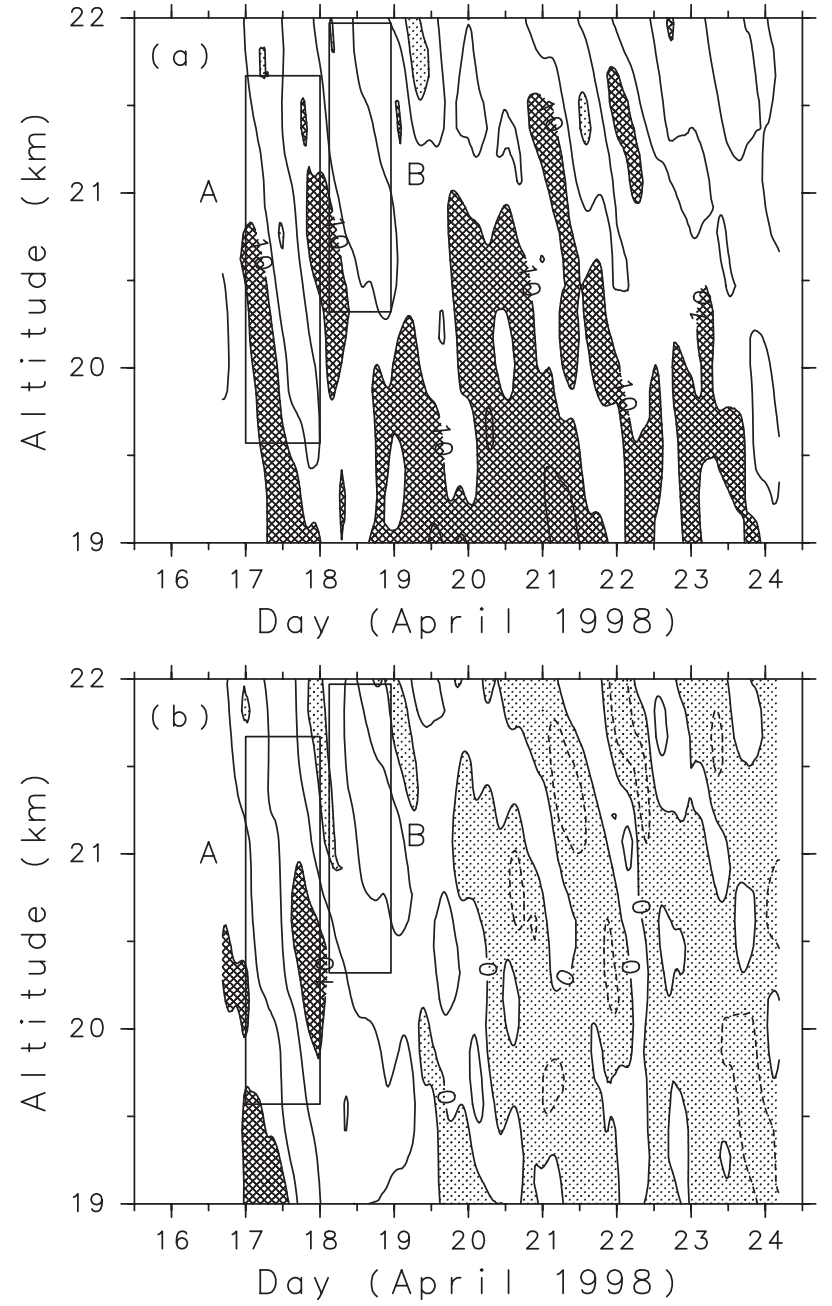

Figure 5. Time-height sections of (a) zonal and (b) meridional winds in the height region of 19-22 km. Contour intervals are $5 \mathrm{~m}$ $\mathrm{s}^{-1}$. Negative regions are lightly shaded, and regions with values larger than $10 \mathrm{~m} \mathrm{~s}^{-1}$ are darkly shaded. Clear wave packets are observed in the region of rectangles $\mathrm{A}$ and $\mathrm{B}$.

ozone variation in the $8-24 \mathrm{~km}$ region is slightly larger than the total ozone variation. This is likely due to the temporal sparseness of the EP/TOMS measurements (once a day) compared to the ozonesonde measurements ( 3 times a day).

[11] In order to examine the horizontal extent of the ozone lamina we compare the vertical profiles of ozone mixing ratio at Shigaraki $\left(34.9^{\circ} \mathrm{N}, 136.1^{\circ} \mathrm{E}\right)$ with those in Tsukuba (Tateno) $\left(36.1^{\circ} \mathrm{N}, 140.1^{\circ} \mathrm{E}\right)$ and Sapporo $\left(43.1^{\circ} \mathrm{N}, 141.3^{\circ} \mathrm{E}\right)$ from operational observations taken by the Japan Meteorological Agency about once a week. Dashed curves in Figures $3 \mathrm{a}$ and $3 \mathrm{~b}$ show vertical profiles of ozone mixing ratio at 0600 UT on 20 April in Tsukuba and at 0600 UT on 21 April in Sapporo, respectively. The vertical profiles of ozone mixing ratio at the closest time at Shigaraki are also shown by solid curves for comparison. An ozone lamina similar to that at Shigaraki was observed at $\theta=500 \mathrm{~K}$ in Tsukuba, while no laminated structure was observed in Sapporo. This indicates that while this ozone lamina is horizontally extended more than $\sim 500 \mathrm{~km}$ (distance between Shigaraki and Tsukuba), the northern end of the ozone lamina was located between Tsukuba and Sapporo.

\section{Contribution of Inertia-Gravity Waves}

[12] Figure 4 shows time-height sections of the zonal $(u)$ and meridional $(v)$ winds during the observation period. Displayed winds are smoothed with low pass filters with cutoff lengths of $0.6 \mathrm{~km}$ in the vertical and 10 hours in time. The subtropical westerly jet was located around a height region of $12-14 \mathrm{~km}$. The tropopause denoted by solid circles was situated at around $12 \mathrm{~km}$ at the beginning of the observation, lowered to $9 \mathrm{~km}$ on 18 April when the ozone lamina appeared at $18 \mathrm{~km}$, and ascended to $14 \mathrm{~km}$ by 20 April. The meridional wind in the upper troposphere varied from northward to southward on 18 April. These variations of the tropopause height and meridional wind are due to passage of a cutoff cyclone in the troposphere (not shown). Distinct wavelike structures with downward phase propagation are found in the height region of $19-22 \mathrm{~km}$ (see contours of $5 \mathrm{~m} \mathrm{~s}^{-1}$ for $u$ and $0 \mathrm{~m} \mathrm{~s}^{-1}$ for $v$ ), which is similar to that detected by Sato et al. [1997] by the MU radar observation over 3 weeks in April 1995. Figure 5 shows time-height sections of $u$ and $v$ in the height region of $19-22 \mathrm{~km}$. The ground-based wave period is $20-40$ hours. The vertical wavelength is $1-4 \mathrm{~km}$. The wave period and vertical wavelength suggest that the wavelike structures are likely due to inertia-gravity waves. In this section, two distinct wave packets indicated by rectangles $\mathrm{A}$ and $\mathrm{B}$ in Figure 5 are analyzed in detail.

[13] A wave parameter estimation was performed by examining the temporal and vertical variations of the horizontal wind vector (hodograph) following Sato et al. [1997], under the assumption that the wavelike structures are due to inertia-gravity waves. Ground-based horizontal phase velocities, $c$, and other wave parameters are summarized in Table 1. The difference between two values of $c$ estimated by independent methods is small in both cases, supporting the inference that the wavelike structures are due to inertia-gravity waves. In both cases the vertical wavelength, $2 \pi / m$, takes negative values, indicating that the inertia-gravity waves propagate energy upward.

[14] Using the obtained parameters, we estimated the perturbation of ozone mixing ratio associated with the inertia-gravity waves. The fluctuation of ozone mixing ratio due to inertia-gravity waves can be written as

$$
\chi^{\prime}=\operatorname{Re}\left[\frac{i}{\hat{\omega}}\left(\frac{\partial \bar{\chi}}{\partial x} u^{\prime}+\frac{\partial \bar{\chi}}{\partial y} v^{\prime}+\frac{\partial \bar{\chi}}{\partial z} w^{\prime}\right)\right]
$$

where $\hat{\omega}$ is the intrinsic wave frequency, and $\chi^{\prime}$ and $\bar{\chi}$ are the perturbation and background distributions of ozone mixing ratio, respectively [cf., Teitelbaum et al., 1994, 1996; Eckermann et al., 1998]. Since the zonal gradient of background ozone mixing ratio is generally much smaller than the meridional one in the lower stratosphere, the zonal gradient of background ozone mixing ratio is neglected. Assuming that the vertical and meridional gradients of ozone mixing ratio in the $19-22 \mathrm{~km}$ region are $0.7 \mathrm{ppmv} \mathrm{km}{ }^{-1}$ from the ozonesonde data at Shigaraki and $7 \times 10^{-4} \mathrm{ppmv} \mathrm{km}^{-1}$ from data at Kagoshima $\left(31.6^{\circ} \mathrm{N}, 130.6^{\circ} \mathrm{E}\right)$ and Tsukuba $\left(36.1^{\circ} \mathrm{N}\right.$, $\left.140.1^{\circ} \mathrm{E}\right)$, respectively, the estimated amplitudes of ozone perturbation are $0.080 \mathrm{ppmv}$ for case $\mathrm{A}$ and $0.125 \mathrm{ppmv}$ for

Table 1. Wave Parameters of the Inertia-Gravity Waves Observed at Shigaraki (Figure 5) ${ }^{\mathrm{a}}$

\begin{tabular}{cccccccccc}
\hline Case & $\begin{array}{c}\psi, \\
\mathrm{deg}\end{array}$ & $\begin{array}{c}2 \pi / \omega, \\
\mathrm{h}\end{array}$ & $\begin{array}{c}2 \pi / \hat{\omega}, \\
\mathrm{h}\end{array}$ & $\begin{array}{c}2 \pi / k, \\
\mathrm{~km}\end{array}$ & $\begin{array}{c}2 \pi / m, \\
\mathrm{~km}\end{array}$ & $\begin{array}{c}a, \\
\mathrm{~m} \mathrm{~s}^{-1}\end{array}$ & $\begin{array}{c}b, \\
\mathrm{~m} \mathrm{~s}^{-1}\end{array}$ & $\begin{array}{c}c, \\
\mathrm{~m} \mathrm{~s}^{-1}\end{array}$ & $\begin{array}{c}\hat{c}, \\
\mathrm{~m} \mathrm{~s}^{-1}\end{array}$ \\
\hline $\mathrm{A}$ & 183 & 23.0 & 18.5 & 1450 & -3.2 & 4.6 & 4.1 & $17.6(14.9)$ & 21.8 \\
$\mathrm{~B}$ & 165 & 31.4 & 14.1 & 480 & -2.2 & 4.5 & 3.0 & $4.2(5.5)$ & 9.4 \\
\hline
\end{tabular}

${ }^{\mathrm{a}}$ The $\psi$ is the direction of horizontal wavevector (angle taken anticlockwise from the eastward direction), $\omega(\hat{\omega})$ the ground based (intrinsic) wave frequency, $k(m)$ the horizontal (vertical) wavenumber, $a(b)$ the horizontal wind amplitude parallel to (perpendicular to) the horizontal wavevector, $c(\hat{c})$ the ground-based (intrinsic) horizontal phase velocity directly estimated from the hodograph analysis, and the value of $c$ in parentheses is an estimate from the Doppler relation. 


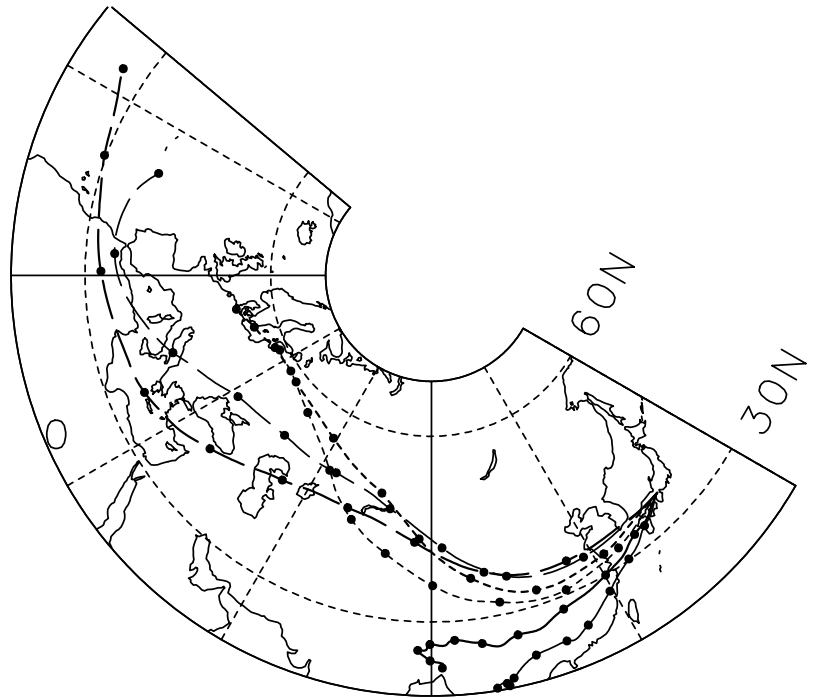

$90 E$

Figure 6. Backward trajectories over 10 days on six isentropes, starting at Shigaraki at 1900 UT on 19 April when the ozone mixing ratio at 460 and $480 \mathrm{~K}$ was enhanced. Thick dashed, thin dashed, thick dotted, thin dotted, thick solid, and thin solid lines represent the trajectories on $420,440,460,480,500$, and $520 \mathrm{~K}$ isentropic surfaces, respectively. Solid circles on the trajectories indicate 1-day intervals.

case B, which are much smaller than the observed amplitude exceeding $0.5 \mathrm{ppmv}$ at $20 \mathrm{~km}$ (see Figure 1). In addition, the period and the downward phase propagation of the inertia-gravity waves are obviously different from those of the observed ozone lamina. Therefore it is concluded that the observed inertia-gravity waves did not contribute to the formation of the observed ozone lamina.

[15] We investigated the contribution of gravity waves to the formation of ozone laminae during the whole observation period using the perturbations of ozone mixing ratio and potential temperature. We assumed that motions are adiabatic, in other words, the ozone mixing ratio and potential temperature are conserved. It is also safely assumed that their vertical gradients are much larger than their horizontal gradients. In this case, gravity waves cause fluctuations of ozone mixing ratio and potential temperature mostly by their vertical motions. Thus the ozone and potential temperature perturbations due to gravity waves are written as

$$
\begin{aligned}
& \chi_{G W}^{\prime}=\eta^{\prime} \frac{\partial \bar{\chi}}{\partial z}, \\
& \theta_{G W}^{\prime}=\eta^{\prime} \frac{\partial \bar{\theta}}{\partial z}
\end{aligned}
$$

where $\eta^{\prime}$ is the vertical displacement associated with gravity waves and the subscript GW indicates the gravity wave component of the perturbation. Since, in the lower stratosphere the large-scale motions of Rossby waves barely displace the isentropic surfaces and diabatic effects can be neglected, it is assumed that $\theta^{\prime}=\theta_{G W}^{\prime}$

except in the vicinity of the tropopause. Then, the ozone perturbation due to gravity waves can be written as

$$
\chi^{\prime} G W=\theta^{\prime}\left(\frac{\partial \bar{\theta}}{\partial z}\right)^{-1} \frac{\partial \bar{\chi}}{\partial z}
$$

Here, in order to obtain the perturbation and background profiles of ozone and potential temperature, a bandpass filter with cutoff lengths of 0.5 and $5 \mathrm{~km}$ in the vertical and a low-pass filter with a cutoff length of $5 \mathrm{~km}$ in the vertical are used, respectively. The root mean square of the ozone perturbation due to gravity waves $\left(\sqrt{\overline{\chi_{G W}^{\prime}}}\right)$ is estimated at 0.060 ppmv, which is only $25 \%$ of that of observed ozone perturbation $\left(\sqrt{\chi^{12}} \approx 0.25 \mathrm{ppmv}\right)$. This result indicates that the contribution of gravity waves to the ozone fluctuations is small in the $18-22 \mathrm{~km}$ height region during the observation period.

\section{Contribution of Large-Scale Motions}

\subsection{Backward Trajectory Analysis}

[16] Since the radiative cooling is $\sim 5 \mathrm{~K} \mathrm{week}^{-1}$ around the $500 \mathrm{~K}$ isentropic surface in midlatitudes [Knudsen and Carver, 1994], the variability of large-scale vertical motions in the stratosphere is assumed to be too small to produce the observed irregularity in ozone mixing ratio. A possible cause of the ozone lamina is the large-scale quasi-isentropic advection as discussed below.

[17] In order to examine the origins of the air parcels observed over Shigaraki, we performed a backward trajectory analysis using a numerical code developed by the Earth Observation Research Center (EORC), National Space Development Agency of Japan (NASDA). The calculation is based on temperature and winds of the ECMWF operational analysis on 10 isobaric levels between 400 and $10 \mathrm{hPa}$. Used are twice daily data on a $2.5^{\circ} \times 2.5^{\circ}$ horizontal mesh; interpolation is done linearly in space and time. A second-order Runge-Kutta scheme with a time step of 1 hour is employed for trajectory integration. The backward trajectories are computed on 10 isentropic surfaces from 400 to $580 \mathrm{~K}$ with a $20 \mathrm{~K}$ interval. Because the reliable isentropic trajectory period is 10 days at most in the lower stratosphere [Knudsen and Carver, 1994] and the lifetime of ozone laminae is considered to be a few weeks [Reid et al., 1998], the trajectory calculation period is taken to be 10 days.

[18] Figure 6 shows the backward trajectories started at Shigaraki at 1900 UT on 19 April when the ozone mixing ratio was enhanced between 450 and $490 \mathrm{~K}$ (around $18.5-20 \mathrm{~km}$ ). The trajectories at 460 and $480 \mathrm{~K}$ show that the air parcels with high ozone mixing ratio came from high latitudes (north of $50^{\circ} \mathrm{N}$ ), while the trajectories at $420,440,500$, and $520 \mathrm{~K}$ show that the air parcels with low ozone mixing ratio came from low latitudes. We also computed backward trajectories from other ozonesonde observation times. Most results showed a similar relation between the observed ozone mixing ratios and latitudes where the air parcels were located 7-10 days before (not shown). Therefore it is deduced that the observed ozone variation was caused by advection from different latitude regions. This result is confirmed in a more concrete manner by another method as shown in the next section.

\subsection{Analysis Using the Reverse Domain Filling Method}

[19] In the lower stratosphere both the ozone mixing ratio and potential vorticity (PV) are quasi-conserved for motions following air parcels over a few weeks [e.g., Andrews et al., 1987]. The potential vorticity on the $460 \mathrm{~K}$ isentropic surface and total ozone show similar distributions on 17 April 1998, a typical day on which the trajectory analysis was performed (Figure 7). Since the total ozone is supposed to be representative of the ozone concentration in the lower stratosphere, it is concluded that both PV and ozone 
( a )

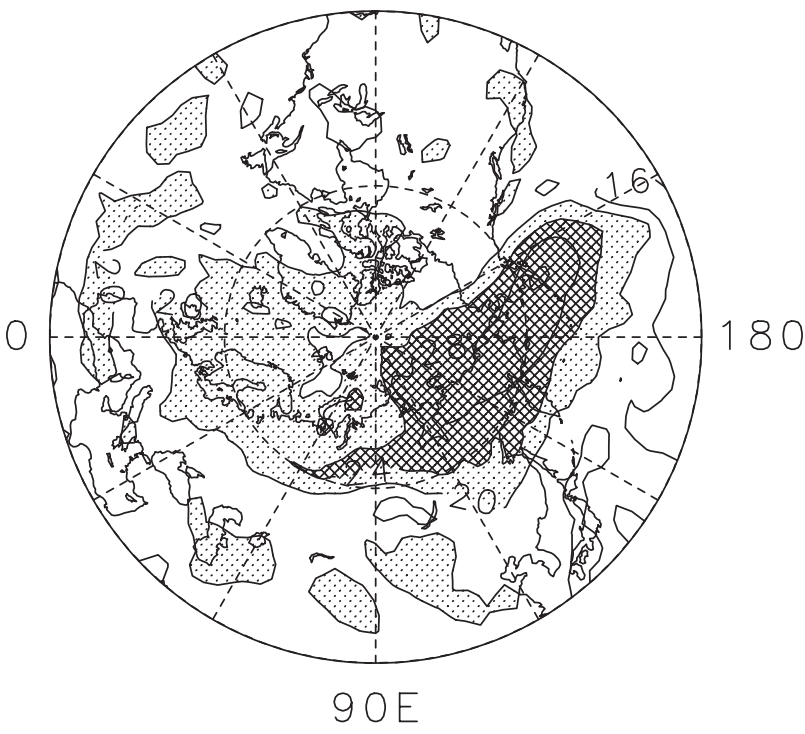

( b )

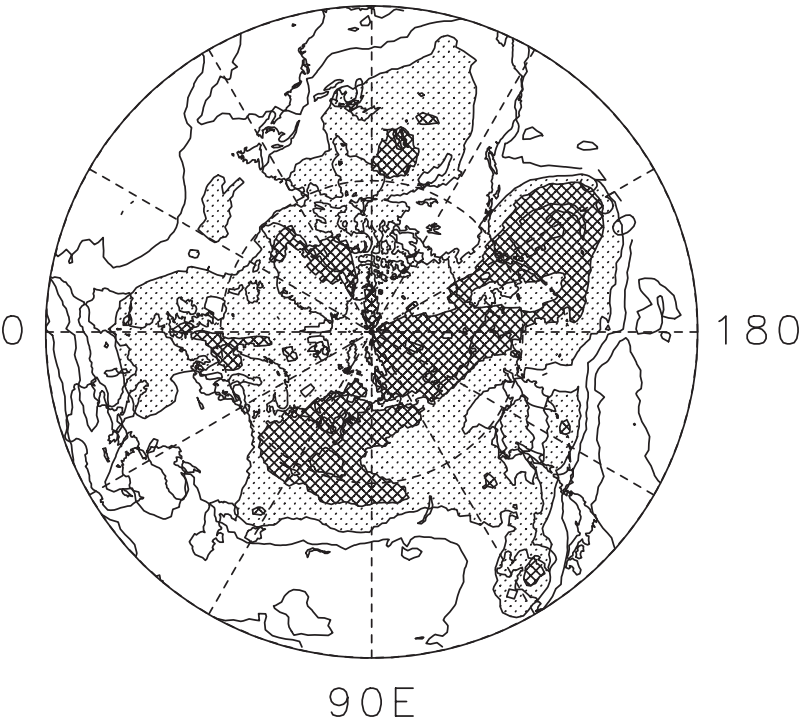

Figure 7. Polar stereo projection maps of (a) potential vorticity on the $460 \mathrm{~K}$ isentropic surface at 1200 UT on 17 April based on the ECMWF operational analysis data and (b) total ozone measured by the EP/TOMS on 17 April. Contour intervals are 4 PVU ( $1 \mathrm{PVU}=1 \times 10^{-6} \mathrm{~K} \mathrm{~kg}^{-1} \mathrm{~m}^{2} \mathrm{~s}^{-1}$ ) and $50 \mathrm{DU}$ for Figures $7 \mathrm{a}$ and $7 \mathrm{~b}$, respectively.

mixing ratio increase with latitude on isentropic surfaces during the observation period at least in the Japanese sector. Thus, if the observed ozone lamina was caused by advection from different latitude regions as the trajectory analysis suggests, PV would have a laminated structure similar to the observed ozone lamina. Here, to show the effect of meridional advection more clearly, we use a modified potential vorticity (MPV $\equiv \operatorname{PV}\left(\theta / \theta_{0}\right)^{-9 / 2}$, where $\theta_{0}$ is set to $420 \mathrm{~K}$ [Lait, 1994]), which does not increase exponentially with height, instead of PV itself. Figure 8 shows the time-height section of MPV at the closest grid point $\left(35^{\circ} \mathrm{N}, 135^{\circ} \mathrm{E}\right)$ to Shigaraki computed with the ECMWF data. Comparing Figure 8 with Figure 1, it is seen that MPV does not have a laminated structure

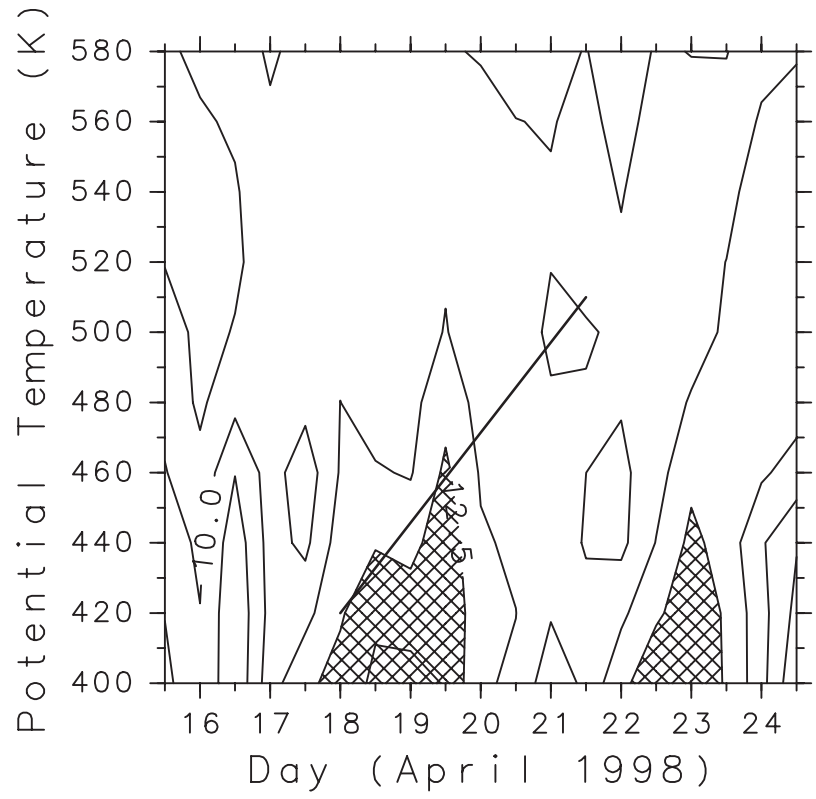

Figure 8. As in Figure 1, but for modified potential vorticity at $35^{\circ} \mathrm{N}, 135^{\circ} \mathrm{E}$ directly calculated with the ECMWF data. Contour intervals are 1.25 PVU. Regions with values larger than 12.5 PVU are shaded. A thick solid line indicates the approximate position of ozone extrema as shown in Figure 1.

corresponding to the ozone lamina. Large values of MPV around $400 \mathrm{~K}$ on 19 April correspond to the cutoff cyclone in the troposphere and not to the ozone lamina. This discrepancy between MPV and ozone mixing ratio may be attributed to too coarse vertical resolution of ECMWF data used in this calculation. While the thickness of ozone lamina is $2-3 \mathrm{~km}$, only three levels $(100$, 70 , and $50 \mathrm{hPa}$ ) are available for the ECMWF data in the height region where the ozone lamina was observed, corresponding to the vertical resolution of $\sim 6 \mathrm{~km}$.

[20] Combining MPV and backward trajectories, it is possible to show "high-resolution" vertical cross sections of the tracer field by a technique called the reverse domain filling method (RDF) [Sutton et al., 1994; O'Neill et al., 1994; Schoeberl and Newman, 1995;

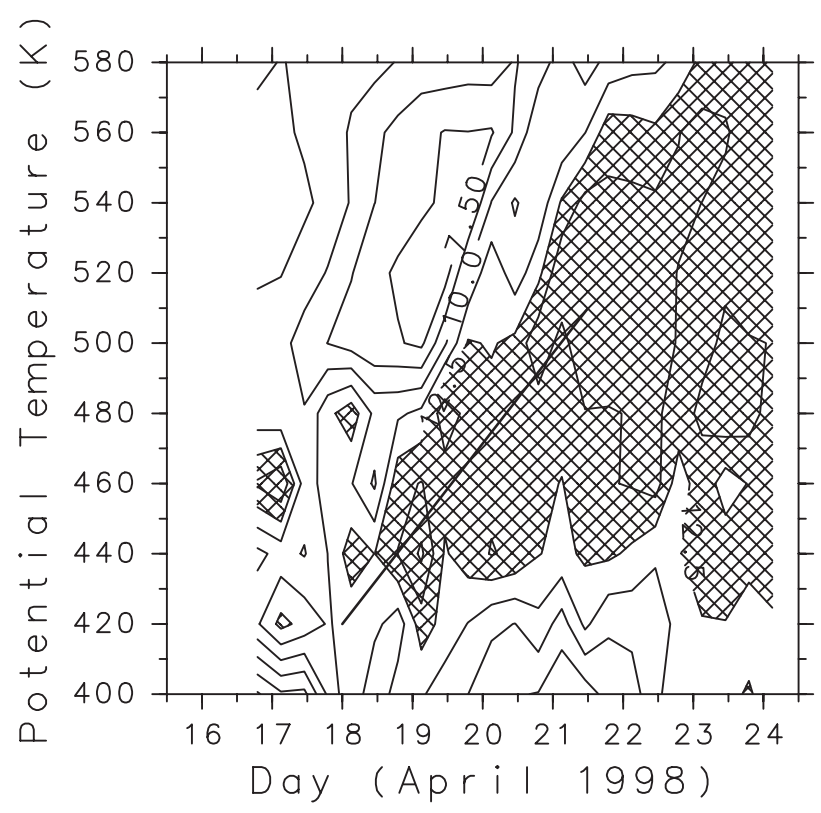

Figure 9. As in Figure 8, but for MPV at Shigaraki reconstructed by RDF calculations. 
(a) 0000 UT on 16 April 1998

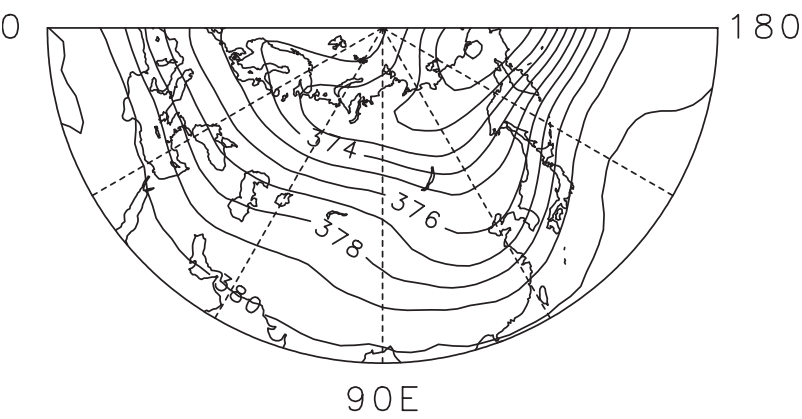

(b) 0000 UT on 16 April 1998

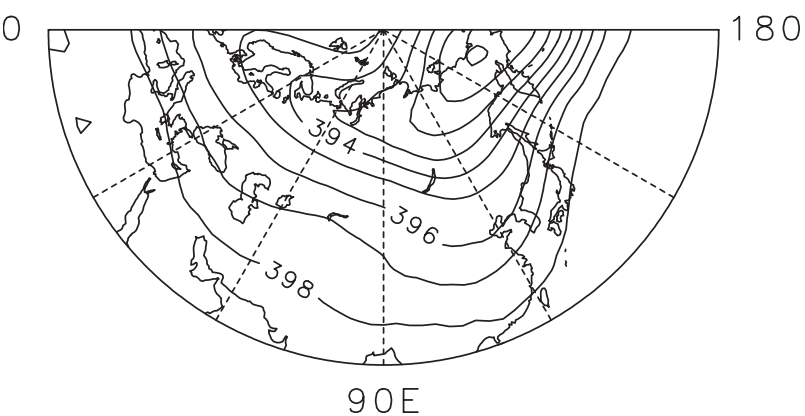

(c) 0000 UT on 16 April 1998

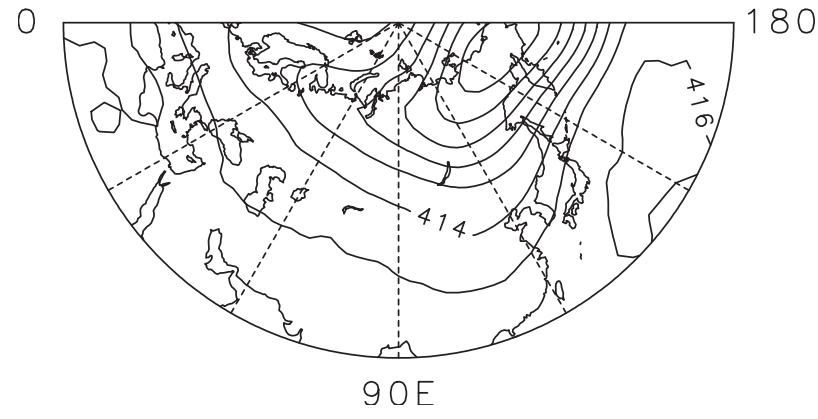

Figure 10. Montgomery stream function on the (a) 420, (b) 460, and (c) $500 \mathrm{~K}$ isentropic surfaces at $0000 \mathrm{UT}$ on 16 April 1998 based on the ECMWF operational analysis data. Contour intervals are $10^{3} \mathrm{~m}^{2} \mathrm{~s}^{-2}$

Newman and Schoeberl, 1995; Newman et al., 1996; Knudsen et al., 1998; Knudsen and Grooß, 2000]. In the present study the parcels on 10 isentropic levels $(400-580 \mathrm{~K}$ at an interval of $20 \mathrm{~K})$ are advected backward in time from Shigaraki over 7 days. The MPV data 7 days before are calculated directly using ECMWF data, and then MPV values where the parcels had been located 7 days before are obtained. Since MPV values are supposed to be quasi-conserved for parcel motions over 7 days, the obtained MPV values are assigned to the original locations of the parcels on the initial date of backward trajectories. By this procedure, the "highresolution" MPV fields are reconstructed. According to theoretical studies, the horizontal and vertical scales of tracer distributions become smaller with the typical e-folding time of $\sim 4$ days in the lower stratosphere [Haynes and Anglade, 1997; Thuburn and Tan, 1997] and the vertical resolution of MPV field directly calculated with the ECMWF data is $\sim 6 \mathrm{~km}$, implying that RDF calculations for 7 days may produce the MPV field with the vertical resolution of $\sim 1 \mathrm{~km}\left(\approx 6 \times e^{-(7 / 4)}\right)$.
[21] Figure 9 shows the time-height section of MPV at Shigaraki reconstructed by RDF calculations. High and low MPV values in Figure 9 correspond to high and low ozone mixing ratios in Figure 1, respectively. The boundary between high and low MPV values moves upward with a speed of $\sim 30 \mathrm{~K} \mathrm{~d}^{-1}$, in agreement with that of the ozone lamina. Moreover, the thickness of the high MPV region is $\sim 50 \mathrm{~K}$ during the period of $18-20$ April, similar to that of the ozone-enhanced layer. This result supports the inference that the ozone lamina was caused by differential advection interleaving vertically air parcels with different ozone mixing ratios.

\subsection{Characteristics of Large-Scale Flow and Differential Advection}

[22] To see the flow structure causing the differential advection, we examined the Montgomery stream function on the 420,460, and $500 \mathrm{~K}$ isentropic surfaces at $0000 \mathrm{UT}$ on 16 April 1998 on Figure 10. The Montgomery stream function is defined by

$$
M=c_{\mathrm{p}} T+\phi,
$$

where $c_{\mathrm{p}}, T$, and $\phi$ denote the specific heat at constant pressure, temperature, and geopotential, respectively [e.g., Andrews et al., 1987]. A similar large-scale wavy structure can be seen in the longitude region of $70^{\circ} \mathrm{E}-160^{\circ} \mathrm{E}$ (the zonal scale of $\sim 8000 \mathrm{~km}$ ) at all levels shown in Figure 10, although the wind speeds along contours are smaller at higher altitudes because of the vertical shear associated with the subtropical westerly jet in the lower stratosphere (see Figure 4). Judged from its horizontal scale, it is suggested that this wavy structure is due to a synoptic-scale Rossby wave. The structure tilts slightly westward with height. In general, trajectories of air parcels are determined by the cumulative effects of advection instead of the instantaneous one. In the present case, however, since this wavy structure was nearly stationary and maintained during the period of 13-18 April (not shown), the backward trajectories obtained in section 5.1 accord roughly with the streamlines in Figure 10. Comparing the contours in Figure 10 with the backward trajectories in Figure 6, some features of each trajectory can be explained as follows:

1. At 420 and $440 \mathrm{~K}$, air parcels were advected largely from $30^{\circ} \mathrm{E}$ to $110^{\circ} \mathrm{E}$ owing to the strong westerly jet during the period of 13-18 April, when the stationary Rossby wave existed. Because they passed through both southward and northward wind regions of the Rossby wave, their latitudinal displacement was limited in the latitude region of $30^{\circ} \mathrm{N}-50^{\circ} \mathrm{N}$.

2. At 460 and $480 \mathrm{~K}$, air parcels were located around $60^{\circ} \mathrm{E}$ on 13 April, and advected to $120^{\circ} \mathrm{E}$ until 18 April. Since, in this longitude region, the southward wind dominated, in association with the Rossby wave (see Figure 10b), the air parcels on these two levels were advected from nearly $60^{\circ} \mathrm{N}$ to $30^{\circ} \mathrm{N}$.

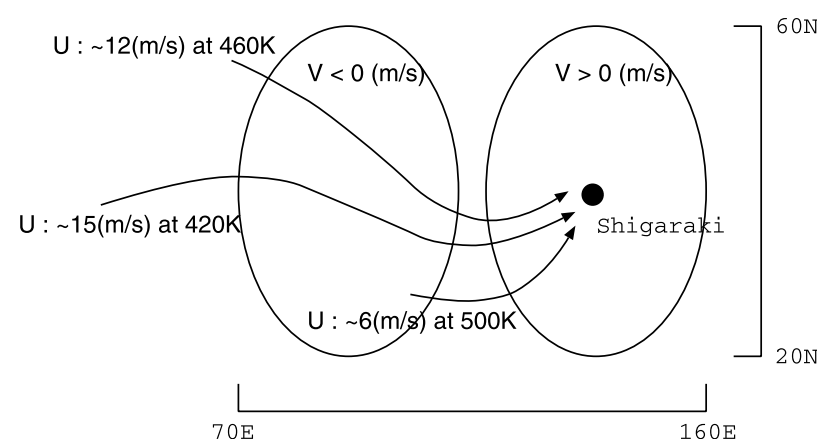

Figure 11. A schematic illustration of the differential advection for the present case. $\mathrm{U}$ and $\mathrm{V}$ denote the zonal and meridional winds, respectively. 
(a) 0000 UT on 20 April 1998
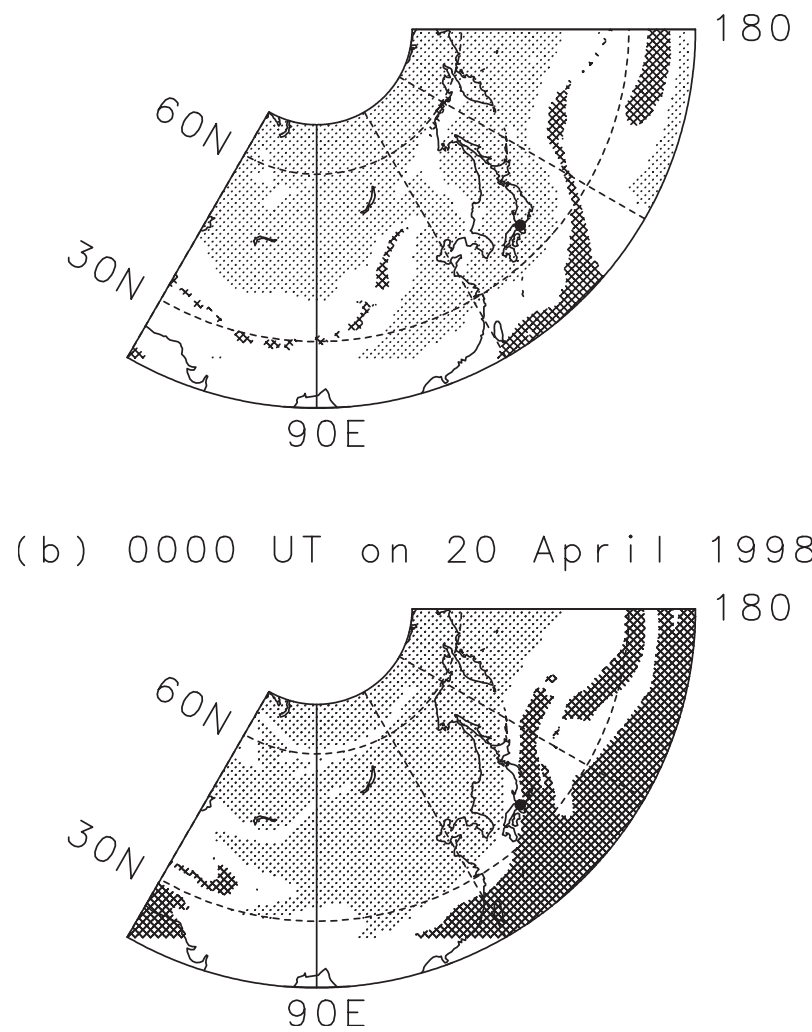

Figure 12. Reconstructed MPV fields on isentropic surfaces of (a) $460 \mathrm{~K}$ and (b) $520 \mathrm{~K}$ at $0000 \mathrm{UT}$ on 20 April 1998. Regions with values larger than 12.5 PVU and smaller than 10 PVU are lightly and darkly shaded, respectively. Solid circles indicate the location of Shigaraki $\left(35^{\circ} \mathrm{N}, 136^{\circ} \mathrm{E}\right)$.

3. At 500 and $520 \mathrm{~K}$, air parcels were advected from $20^{\circ} \mathrm{N}$ to Shigaraki by the weak northward wind between $90^{\circ} \mathrm{E}$ and $135^{\circ} \mathrm{E}$ (see Figure 10c).

[23] Namely, the differential advection was caused by the vertical shear associated with the subtropical westerly jet and the stationary Rossby wave embedded therein. This scenario explains well that ozone enhancement was seen only in the height region around $460 \mathrm{~K}$ on 19 April. This scenario is schematically illustrated in Figure 11.

[24] The ascent of the ozone lamina can also be explained by the vertical wind shear. For simplicity, we assume that the background ozone mixing ratio monotonically increases with latitude and that the zonal flow is steady, having a wind speed of $15 \mathrm{~m} \mathrm{~s}^{-1}$ at $420 \mathrm{~K}$ and $10 \mathrm{~m} \mathrm{~s}^{-1}$ at $480 \mathrm{~K}$ (see Figure 4), respectively. It is expected that air parcels initially located at the western edge of the southward wind region of the Rossby wave would be advected from the highest latitude and have the maximum ozone mixing ratios of all air parcels reaching Shigaraki. Thus we consider that air parcels started at $60^{\circ} \mathrm{E}$, which is the western edge of the southward wind region of the Rossby wave, on 13 April when the Rossby wave appeared. The parcels at 420 and $480 \mathrm{~K}$ took 5 and 7.5 days to reach Shigaraki, respectively. This different timing of arrival of the air parcels resulted in the ozone-enhanced layer ascending with a speed of $24 \mathrm{~K} \mathrm{~d}^{-1}(=60 \mathrm{~K} / 2.5$ days). This value is consistent with the observed ascending speed of the ozone lamina $\left(\sim 25 \mathrm{~K} \mathrm{~d}^{-1}\right)$.

\subsection{Three-Dimensional Structure of Ozone Lamina}

[25] To examine the three-dimensional structure of the ozone lamina, we reconstruct "high-resolution" MPV fields on regular grid points $\left(1^{\circ} \times 1^{\circ}\right)$ on 10 isentropic surfaces $(400-580 \mathrm{~K}$ with a $20 \mathrm{~K}$ interval) using RDF calculations for 7 days. Figure 12 shows the horizontal distribution of reconstructed MPV on the 460 and $520 \mathrm{~K}$ isentropic surfaces at $0000 \mathrm{UT}$ on 20 April. At $460 \mathrm{~K}$ (Figure 12a) a high MPV tongue, which corresponds to the ozone enhancement, is located over Japan, and a filamentary intrusion of low MPV air is seen on the eastern side of the tongue. A similar high MPV tongue is also seen at $520 \mathrm{~K}$ (Figure 12b), though its

\section{(a) 0000 UT on 20 April 1998 (136E)}

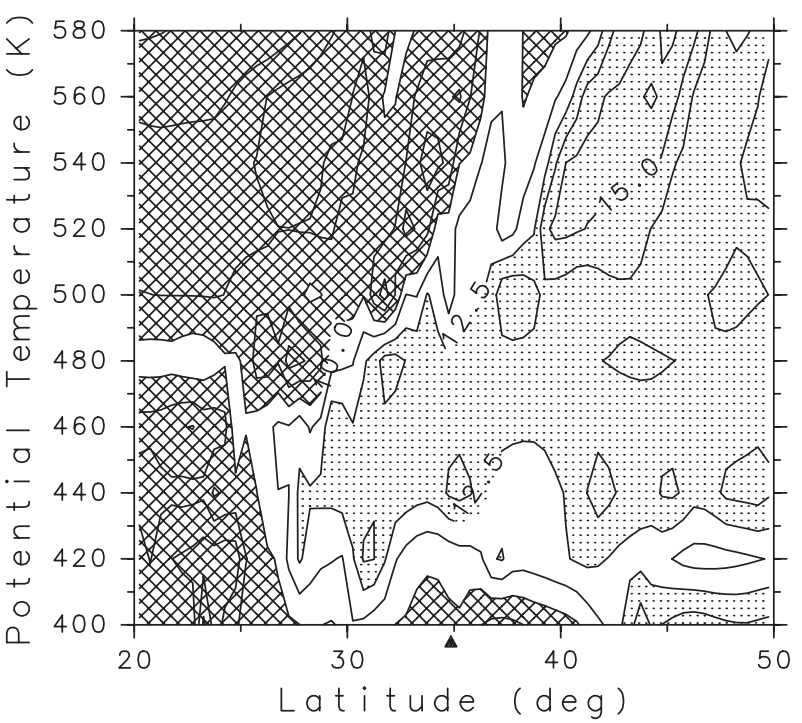

(b) 0000 UT on 20 Apri। 1998 (35N)

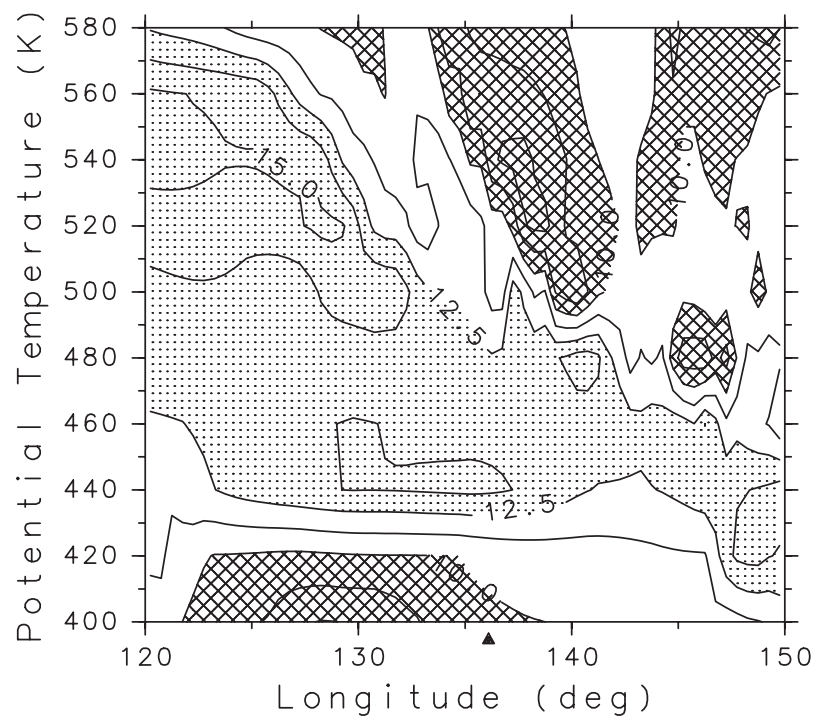

Figure 13. (a) Latitude- and (b) longitude-height sections of reconstructed MPV along the longitude and latitude of Shigaraki $\left(35^{\circ} \mathrm{N}, 136^{\circ} \mathrm{E}\right)$ at $0000 \mathrm{UT}$ on 20 April 1998 , respectively. Contour intervals are 1.25 PVU. Regions with values larger than 12.5 PVU and smaller than 10 PVU are lightly and darkly shaded, respectively. Closed triangles are marked on the bottom axes of Figures $13 \mathrm{a}$ and $13 \mathrm{~b}$ at the latitude and longitude of Shigaraki, respectively. 
location is slightly to the west of that at $460 \mathrm{~K}$. On the other hand, the filament of low MPV air crosses over Shigaraki and extends offshore of Japan near $40^{\circ} \mathrm{N}, 160^{\circ} \mathrm{E}$ at $520 \mathrm{~K}$, indicating the intrusion of subtropical air with low ozone mixing ratio.

[26] Figure 13 shows the latitude- and longitude-height sections of reconstructed MPV along the longitude and latitude of Shigaraki $\left(35^{\circ} \mathrm{N}, 136^{\circ} \mathrm{E}\right)$, respectively. A high MPV sheet with a thickness of $\sim 50 \mathrm{~K}$ is located between the latitudes of $28^{\circ} \mathrm{N}$ and $39^{\circ} \mathrm{N}$, and an intrusion of low MPV air above the high MPV sheet reaches the latitude of $37^{\circ} \mathrm{N}$ in Figure 13a. In the longitude-height section (Figure 13b), while a high MPV region extends from the longitude of $120^{\circ} \mathrm{E}$ to $150^{\circ} \mathrm{E}$, the intrusion of low MPV air has a small zonal extent of $\sim 6^{\circ}$ between the longitudes of $133^{\circ} \mathrm{E}$ and $142^{\circ} \mathrm{E}$. Thus the vertical contrast of high and low MPV air is only seen in the region of $28^{\circ} \mathrm{N}-37^{\circ} \mathrm{N}$ and $133^{\circ} \mathrm{E}-142^{\circ} \mathrm{E}$. These characteristics are in good agreement with the fact that the ozone lamina was seen at Shigaraki $\left(34.9^{\circ} \mathrm{N}, 136.1^{\circ} \mathrm{E}\right)$ and Tsukuba $\left(36.1^{\circ} \mathrm{N}, 140.1^{\circ} \mathrm{E}\right)$ but not seen at Sapporo $\left(43.1^{\circ} \mathrm{N}, 141.3^{\circ} \mathrm{E}\right)$. The zonal and meridional scales of the ozone lamina are much smaller than the horizontal scale of the Rossby wave that contributed to the formation of this ozone lamina.

\section{Summary and Concluding Remarks}

[27] In order to investigate the formation mechanism of ozone laminae in the midlatitude lower stratosphere, we have performed intensive observations with ozonesondes, radiosondes and the MU radar at Shigaraki, Japan, in April 1998. During the observation period we detected an ozone lamina with a thickness of $2-3 \mathrm{~km}$ ascending with a speed of $\sim 1 \mathrm{~km} \mathrm{~d}^{-1}$ in the height region of $18-$ $21 \mathrm{~km}$. While most of the ozone laminae observed in the European and North American continents are short-lived (i.e., several hours [Gibson-Wilde et al., 1997; Orsolini et al., 1997]), the observed ozone lamina over Japan persisted for $\sim 3$ days.

[28] The contribution of inertia-gravity waves to the formation of the ozone lamina was investigated. Although clear inertiagravity waves were seen in the same height region during the observation period, the estimated perturbation in ozone mixing ratio due to the inertia-gravity waves was much smaller than that observed.

[29] The contribution of large-scale quasi-isentropic motions was also examined. Results of a trajectory analysis showed that the ozone lamina was caused by the differential advection of air parcels having different ozone mixing ratios in different latitude regions. The differential advection was due to the vertical shear of the subtropical westerly jet where a stationary Rossby wave was embedded. This implies that large-scale motions concurrent with vertical wind shear can produce much smaller-scale structures than those of the large-scale motions themselves.

[30] The laminated structure was not seen in the time-height section of MPV calculated directly with the ECMWF data. However, the "high-resolution" MPV field obtained by RDF calculations successfully reconstructed a laminated structure similar to the observed ozone lamina in terms of its thickness and ascending speed. The three-dimensional structure of the reconstructed lamina was consistent with ozonesonde observations at other locations (i.e., Tsukuba and Sapporo) as well as that at Shigaraki. These facts indicate that MPV is a good proxy tracer for ozone mixing ratio in the lower stratosphere, and the RDF technique is a powerful method for analyzing small-scale structures.

[31] It is important to determine whether the ozone lamina indicates an irreversible exchange between high and low latitudes. Since the irreversible exchange across a large gradient of ozone mixing ratio may occur in the form of lamination, further statistical studies on ozone laminae are necessary to understand the exchange processes between the inside and outside of the polar vortex and between the stratosphere and troposphere in the midlatitude region. The turbulence induced by gravity wave breaking can cause irreversible mixing of ozone laminae in the vertical, although the gravity waves did not contribute significantly to the formation of the ozone lamina. Therefore, to examine the exchange quantitatively, it is important to take into account both the large-scale advection and small-scale turbulent mixing associated with gravity wave breaking.

[32] It is also a problem to understand how the laminated structure is formed, maintained, and deformed. While rapid deformation of the lamina causes rapid mixing, maintenance of the structure inhibits the mixing. We have shown the formation mechanism of the lamina, but the reason for the temporal change of its structure remains unclear. No analysis to show the cause of the temporal change of the lamina has been presented in this study (because of the limitation of computational resources). However, we hope to be able to address this in future studies.

[33] Acknowledgments. The observation was performed by N. Takegawa, M. Yoshiki, and S. Matsukawa together with the authors. We thank $\mathrm{H}$. Hashiguchi and S. Ogino for their support of our observation. We also acknowledge N. Iwagami for his helpful comments and encouragement, and S. Kawakami for his guidance for the trajectory analysis. The MU radar belongs to and is operated by the Radio Science Center for Space and Atmosphere of Kyoto University. GFD-DENNOU Library was used for drawing figures.

\section{References}

Andrews, D. G., J. R. Holton, and C. B. Leovy, Middle Atmosphere Dynamics, 489 pp., Academic, San Diego, Calif., 1987.

Danielsen, E. F., R. S. Hipskind, W. L. Starr, J. F. Vedder, S. E. Gaines, D. Kley, and K. K. Kelly, Irreversible transport in the stratosphere by internal waves of short vertical wavelength, J. Geophys. Res., 96, $17,433-17,452,1991$

Dobson, G. M. B., The laminated structure of the ozone in the atmosphere, Q. J. R. Meteorol. Soc., 99, 599-607, 1973.

Eckermann, S. T., D. E. Gibson-Wilde, and J. T. Bacmeister, Gravity wave perturbations of minor constituents: A parcel advection methodology, J. Atmos. Sci., 55, 3521-3539, 1998.

Fukao, S., T. Sato, T. Tsuda, S. Kato, K. Wakasugi, and T. Makihira, The MU radar with an active phased array system, 1, Antenna and power amplifiers, Radio Sci., 20, 1155-1168, 1985.

Gibson-Wilde, D. E., R. A. Vincent, C. Souprayen, S. Godin, A. Hertzog, and S. D. Eckermann, Dual lidar observations of mesoscale fluctuations of ozone and horizontal winds, Geophys. Res. Lett., 24, 1627-1630, 1997.

Haynes, P., and J. Anglade, The vertical-scale cascade in atmospheric tracers due to large-scale differential advection, J. Atmos. Sci., 54, $1121-1136,1997$.

Holton, J. R., The production of temporal variability in trace constituents concentrations, in Transport Process in the Middle Atmosphere, edited by G. Visconti and R. Garcia, pp.313-326, D. Reidel, Norwell, Mass., 1987.

Juckes, M. N., and M. E. McIntyre, A high-resolution one-layer model of breaking planetary waves in the stratosphere, Nature, 328, 590-596, 1987.

Knudsen, B. M., and G. D. Carver, Accuracy of the isentropic trajectories calculated for the EASOE campaign, Geophys. Res. Lett., 21, 1199-1202, 1994.

Knudsen, B. M., and J.-U. Grooß, Northern midlatitude stratospheric ozone dilution in spring modeled with simulated mixing, J. Geophys. Res., 105, 6885-6890, 2000.

Knudsen, B. M., W. A. Lahoz, A. O'Neill, and J.-J. Morcrette, Evidence for a substantial role for dilution in northern mid-latitude ozone depletion., Geophys. Res. Lett., 25, 4501-4504, 1998.

Komhyr, W. D., R. A. Barnes, G. B. Brothers, J. A. Lathrop, and D. P. Opperman, Electrochemical concentration cell ozonesonde performance evaluation during STOIC 1989, J. Geophys. Res., 100, 9231-9244, 1995.

Lait, L. R., An alternative form for potential vorticity, J. Atmos. Sci., 51, $1754-1759,1994$.

Mariotti, A., M. Moustaoui, B. Legras, and H. Teitelbaum, Comparison between vertical ozone soundings and reconstruction potential vorticity maps by contour advection with surgery, J. Geophys. Res., 102, 6131$6142,1997$.

Newman, P. A., and M. R. Schoeberl, A reinterpretation of the data from the NASA stratosphere-troposphere exchange project, Geophys. Res. Lett., 22, 2501-2504, 1995. 
Newman, P. A., et al, Measurements of polar vortex air in the midlatitudes, J. Geophys. Res., 101, 12,879-12,891, 1996.

O’Neill, A., W. L. Grose, V. D. Pope, H. Maclean, and R. Swinbank, Evolution of the Stratosphere during Northern Winter 1991/92 as Diagnosed from U.K. Meteorological Office Analyses, J. Atmos. Sci., 51, 2800-2817, 1994.

Orsolini, Y. J., On the formation of ozone laminae at the edge of the Arctic polar vortex, Q. J. R. Meteorol. Soc., 121, 1923-1941, 1995.

Orsolini, Y. J., G. Hansen, U.-P. Hoppe, G. L. Manney, and K. H. Fricke, Dynamical modeling of wintertime lidar observations in the Arctic: Ozone laminae and ozone depletion, Q. J. R. Meteorol. Soc., 123, $785-800,1997$.

Pierce, R. B., and W. B. Grant, Seasonal evolution of Rossby and gravity wave induced laminae in ozonesonde data obtained from Wallops Island, Virginia, Geophys. Res. Lett., 25, 1859-1862, 1998.

Plumb, R. A., D. W. Waugh, R. J. Atkinson, P. A. Newman, L. R. Lait M. R. Schoeberl, E. V. Browell, A. J. Simmons, and M. Loewenstein, Intrusions into the lower stratosphere Arctic vortex during the winter of 1991-1992, J. Geophys. Res., 99, 1089-1105, 1994.

Reid, S. J., and G. Vaughan, Lamination in ozone profiles in the lower stratosphere, Q. J. R. Meteorol. Soc., 117, 825-844, 1991.

Reid, S. J., and G. Vaughan, Occurrence of ozone laminae near the boundary of the stratosphere polar vortex, J. Geophys. Res., 98, 8883-8890, 1993.

Reid, S. J., G. Vaughan, N. J. Mitchell, I. T. Prichard, H. J. Smit, T. S. Jorgensen, C. Varotsos, and H. de Backer, Distribution of ozone laminae during EASOE and the possible influence of inertia-gravity waves, Geophys. Res. Lett., 21, 1479-1482, 1994.

Reid, S. J., et al, A study of ozone laminae using diabatic trajectories, contour advection and photochemical trajectory model simulations, $J$ Atmos. Chem., 30, 187-207, 1998.

Sato, K., D. J. O'Sullivan, and T. J. Dunkerton, Low-frequency inertiagravity waves in the stratosphere revealed by three-week continuous observation with the MU radar, Geophys. Res. Lett., 24, 1739-1742, 1997.
Schoeberl, M. R., and P. A. Newman, A multiple-level trajectory analysis of vortex filaments, J. Geophys. Res., 100, 25,801-25,815, 1995.

Sutton, R. T., H. Maclean, R. Swinbank, A. O'Neill, and F. W. Taylor, High-resolution stratospheric tracer fields estimated from satellite observations using Lagrangian trajectory calculations, J. Atmos. Sci., 51, 2995-3005, 1994.

Teitelbaum, H., J. Ovarlez, H. Kelder, and F. Lott, Some observations of gravity-wave-induced structure in ozone and water vapour during EASOE, Geophys. Res. Lett., 21, 1483-1486, 1994.

Teitelbaum, H., M. Moustaoui, J. Ovarlez, and H. Kelder, The role of atmospheric waves in the laminated structure of ozone profiles at high latitude, Tellus, Ser. A, 48, 442-445, 1996.

Thuburn, J., and D. G. H. Tan, A parameterization of mixdown time for atmospheric chemicals, J. Geophys. Res., 102, 13037-13049, 1997.

Tuck, A. F., et al, Polar stratospheric cloud processed air and potential vorticity in the Northern Hemisphere lower stratosphere at mid-latitudes during winter, J. Geophys. Res., 97, 7883-7904, 1992.

Waugh, D. W., et al, Transport out of the lower stratospheric Arctic vortex by Rossby wave breaking, J. Geophys. Res., 99, 1071-1088, 1994.

World Meteorological Organization, Scientific assessment of ozone depletion: 1998, World Meterol. Org. Rep.44, Geneva, 1998.

M. Fujiwara, Radio Science Center for Space and Atmosphere, Kyoto University, Kyoto 611-0011, Japan. (fuji@kurasc.kyoto-u.ac.jp)

K. Kita and Y. Tomikawa, Research Center for Advanced Science and Technology, University of Tokyo, Tokyo 153-8904, Japan. (tomikawa@ nipr.ac.jp)

T. Sano, Earth Observation Research Center, National Space Development Agency of Japan, Tokyo 106-0032, Japan. (sano@eorc.nasda.go.jp)

K. Sato, National Institute of Polar Research, Tokyo 173-8515, Japan. (kaoru@nipr.ac.jp)

M. Yamamori, Center for Climate System Research, University of Tokyo, Tokyo 153-8904, Japan. (yamamori@ccsr.u-tokyo.ac.jp) 